\title{
Shape Proposal and Electric Field Distribution of Horizontal Lightning Conductor
}

\author{
Young Sun Kim
}

\begin{abstract}
Horizontal lightning conductor is installed horizontally on the top or side of the building. It uses specific materials and wires or rods of minimum thickness. In the horizontal conductor system, a horizontal conductor is laid on top of the building to be protected and absorbs the lightning through it. And the lightning current is safely discharged to the earth through the conductor connecting this to the ground. The starting point of the discharge current of the lightning strikes depends on the sectional shape of the horizontal conductor. In this paper, a new shape is proposed through electric field analysis in order to find the optimum shape that can lower the discharge start voltage according to the sectional shape of the horizontal conductor. Two - dimensional electrostatic field analysis was carried out for the electric field analysis, and the maximum electric field was analyzed at the upper part of the horizontal conductor for comparative analysis. This study is considered to be helpful in designing or constructing horizontal conductors.
\end{abstract}

Keywords: Corona discharge, Electric field distribution, Electrostatic field, Horizontal lightning conductor.

\section{INTRODUCTION}

$\mathrm{T}$ he lightning protection system of buildings is intended to eliminate life-threatening damage caused by increasing lightning strikes according to various complex conditions. In addition, it is a planned facility to prevent direct or indirect damage to objects such as buildings to be protected and to minimize the degree of damage. Lightning occurs in a natural environment, and its intensity and frequency depend on the seasonal conditions, geology, and topography of the area. Therefore, domestic and international countries should specify the principles and guidelines of the lightning protection method appropriate to their climate condition, geographical characteristics and cultural conditions, and detail the regulations and guidelines such as the details, and apply the contents to the protection facilities such as buildings and facilities efficiently[1].

In the horizontal conductor system, a horizontal conductor is installed on the upper part of the building to be protected, which draws the lightning stroke and discharges the lightning current safely to the ground through the conductor connecting this to the ground. This principle is widely used is the overhead ground wire of the transmission line. The protection angle of the horizontal conductor is essentially the same as the protection angle of the air terminal lightning rod.

The horizontal conductor directly installed on the building

Revised Manuscript Received on July 22, 2019.

Young Sun Kim *, Department of Electrical and Electronic Engineering, Joongbu University, Goyang, Gyeonggi-Do, South Korea. Email: yskim@joongbu.ac.kr is also called the ridge top conductor. Horizontal conductors may be placed vertically on the roof of a building or installed close to a building. In addition to installing the horizontal conductor on the ridge near the building, most of it is buried and only a part or surface is exposed to the air. Also, in case of dangerous goods storage or important protection, the separation distance should be maintained to prevent counter-flashover with the protection target by using independent overhead ground wire to make it completely electrically independent[2-4].

In order to protect buildings from horizontal lightning conductors, discharge currents must be initiated from thunderstorms. The horizontal conductor as well as the lightning rod is also considered to have a greater protection effect when the discharge starting voltage of the thunderstorm starts early. In this paper, five cross - sectional shapes of horizontal conductors are presented. The proposed shape was changed considering the area and shape from the circular type. The area of the proposed model is compared with the circular type, some of them are the same, some of them are smaller, and some of them are larger. Two-dimensional electrostatic field analysis was carried out under constant boundary conditions for the electric field analysis, and the maximum field values were compared and discussed with the shape.

By analyzing the electric field of the horizontal conductor, it is possible to verify the practicality of the numerical analysis method and realize how important the theoretical approach is in the field.

\section{HORIZONTAL LIGHTNING CONDUCTOR AND CORONA DISCHARGE CURRENT}

The conductors used in the horizontal conductor method include copper, aluminum and stainless(SUS). Table-I shows the characteristics. The characteristics of the corona discharge current that occurs depending on the material and shape of the horizontal conductor can improve the efficiency of the lightning protection. Lightning protection method is lightning rod method and horizontal conductor method. Horizontal conductor is constructed by mesh method and its characteristics are as follows. Mesh methods are considered to protect the entire surface of the building and for the purpose of protecting a flat surface, the following conditions must be satisfied. First, the lightning conductor should be arranged as shown in the Fig. 1. Second, mesh spacing of the mesh net should be as shown in Table-I. Third, the lightning current is connected to the ground through at least two metal routes. Finally, the lightning conductor should be as short and straight as possible[5]. 
Table- I: Comparison of horizontal lightning conductor according to material property

\begin{tabular}{|c|c|c|c|}
\hline Material & Copper $(\mathbf{C u})$ & Aluminum(Al) & Stainless(SUS) \\
\hline $\begin{array}{l}\text { Photo } \\
\text { image }\end{array}$ & & & \\
\hline $\begin{array}{l}\text { Physical } \\
\text { characteris } \\
\text { tics }\end{array}$ & $\begin{array}{l}\text { Good } \\
\text { conductivity }\end{array}$ & Strong durability & $\begin{array}{l}\text { Relatively } \\
\text { excellent tension } \\
\text { force }\end{array}$ \\
\hline $\begin{array}{l}\text { Environme } \\
\text { ntal aspect }\end{array}$ & $\begin{array}{l}\text {-Thermal } \\
\text { shrinkage \& } \\
\text { expansion } \\
\text {-Black } \\
\text { corrosion } \\
\text {-It's not good } \\
\text { to look at the } \\
\text { shagging shape } \\
\text { when installed. }\end{array}$ & $\begin{array}{l}\text {-No thermal } \\
\text { shrinkage and } \\
\text { expansion } \\
\text {-Slow corrosion } \\
\text { and no color } \\
\text { change } \\
\text {-Aluminum color } \\
\text { and architecture } \\
\text { match well. }\end{array}$ & $\begin{array}{l}\text {-No thermal } \\
\text { shrinkage and } \\
\text { expansion } \\
\text {-No corrosion } \\
\text {-No color change }\end{array}$ \\
\hline $\begin{array}{l}\text { Constructi } \\
\text { ve aspect }\end{array}$ & $\begin{array}{l}\text {-Relatively } \\
\text { heavy( } 3 \text { times } \\
\text { that of } \mathrm{Al})\end{array}$ & $\begin{array}{l}\text {-Easy to install } \\
\text { and process } \\
\text {-Relatively } \\
\text { light }(1 / 3 \text { of } \mathrm{Cu})\end{array}$ & $\begin{array}{l}\text {-Heavier than } \mathrm{Al} \\
\text {-Higher price } \\
\text { than } \mathrm{Al}\end{array}$ \\
\hline $\begin{array}{l}\text { Economica } \\
\text { l aspect }\end{array}$ & $\begin{array}{l}\text {-Relative high } \\
\text { price } \\
-3 \text { times that of } \\
\mathrm{Al}\end{array}$ & $\begin{array}{ll}-30 \% & \text { price } \\
\text { against } \mathrm{Cu} & \end{array}$ & $\begin{array}{ll}-50 \% & \text { price } \\
\text { against } \mathrm{Cu} & \end{array}$ \\
\hline
\end{tabular}

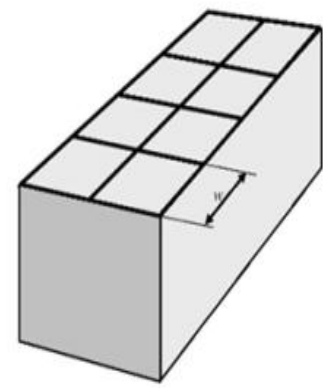

(a) Flat structure

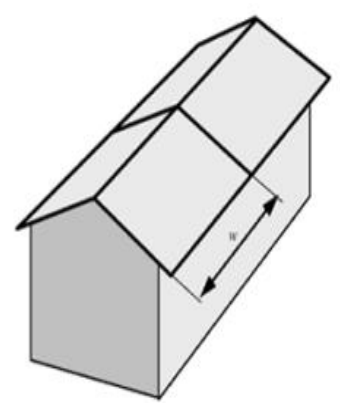

(b) Sloped roof
Fig. 1.Example of horizontal lightning conductor.

In the case of negative thunderstorms, a positive polarity is formed in the earth, and a positive polarity discharge is proposed by Kip in 1938 as an explanation for the onset of a positive point discharge. The start of the emission of the positive electrode depends on the availability of free electrons in the air around the needle electrode of the electrode[6].

When there are free electrons in the air above the electrode affected by a strong electric field, electrons escaping from the neutral molecule are generated by accelerating free electrons in the upward direction of the needle electrodes. At this time, the free electrons necessary for starting the ionization can be generated from a cosmic ray or the like. The beginning of the ionization requires an electric field that is stronger than the electric field needed to maintain the ionization. The ionization lasts as a result of the ion repulsion until the potential becomes equi-potential at the initial potential and the terminal electrode of the terminal period. At this time, the intensity E/p of the relative electric field rises above 90 [V/cm/torr] and a new ionization occurs. A new breakdown of the positive ions generated from this time is increased. In a strong electric field

in this state, many free electrons can move in the lightning rod after the start of ionization. When the electric field around the electrodes is rapidly increased, the ionization proceeds into the air, which forms a positive streamer that can propagate electrons under the influence of the surrounding electric field[6].

The lightning protection system shall be capable of reducing the potential between the thunderstorm and the earth to protect the building from lightning. In addition, the lightning protection system is required to induce the electric charge because the induced electric charge of the place where the lightning strikes must be released, and the strong electric field is generated by the air insulation property and thunderstorm.

Most of the lightning energy is released into the atmosphere through the ionization process - natural radiation by the thunderstorm electric field. Lightning protection is focused on anticipating and reducing damage by sustained release of charge induced by the thunderstorm to the ground or to the protected object. In other words, the lightning protection continuously changes the state of the corona discharge current flowing through the leading edge when the electric field induced by the charge of thundercloud increases from $0[\mathrm{kV} / \mathrm{m}]$ to $100[\mathrm{kV} / \mathrm{m}]$ by continuously discharging the electric charge induced in the protected area[7-10].

The steady state has a field strength of less than $10[\mathrm{kV} / \mathrm{m}]$ and there is little corona discharge current flowing through the tip. However, the intensity of the electric field is gradually increased to start discharging at an electric field intensity of $10[\mathrm{kV} / \mathrm{m}]$ or more. Ionization occurs when the electrons are separated from the neutral particles around the tip, and other neutral particles fill the voids and the ionization is repeated. The corona discharge current generated by the ionizing action increases exponentially with the rise of the leading edge potential, and the corona discharge current generated as the ionizing action occurs in the lower field is further increased[11].

Discharge begins when the ion current increases at a specific point when the streamer is generated by further increasing the electric field intensity and the ions generated around the tip due to the wind or electric field rapidly disappear due to dispersion or recombination. Such a streamer proceeds in the form of a straight line and induces a lightning discharge[ 3,4$]$.

\section{MATHEMATICAL MODELING FOR ELECTROSTATIC FIELD ANALYSIS}

Two-dimensional finite element analysis of electrostatic field was performed for the electric field analysis of horizontal conductor. In this chapter, the Poisson equation, which is the governing equation using the electric scalar potential, is presented from the electrostatic Maxwell equation. In the case of electrostatic field, the system phenomenon does not change with time. Therefore, the analysis is performed using two basic assumptions of the electrostatic field and auxiliary equations indicating the medium relation. 


$$
\begin{aligned}
& \nabla \times \vec{E}=0 \\
& \nabla \cdot \vec{D}=\rho_{v} \\
& \vec{D}=\varepsilon \vec{E}
\end{aligned}
$$

Where $\vec{E}$ denotes electric field strength, $\vec{D}$ is the electric flux density and $\rho_{v}$ is the charge density. The electric field strength expressed by the electric scalar potential is as follows.

$$
\vec{E}=-\nabla \varphi
$$

Finally, the governing equation for the electrostatic field analysis can be expressed as (5). After calculating the potential in this equation, the electric field intensity and distribution can be determined using this potential.

$$
-\nabla \cdot(\varepsilon \nabla \varphi)=\rho_{v}
$$

In order to discretize the above governing equations by the finite element analysis, the second-order partial differential equation of the two dimension region is expressed as (6).

$$
\frac{\partial}{\partial x}\left(\varepsilon \frac{\partial \varphi}{\partial x}\right)+\frac{\partial}{\partial y}\left(\varepsilon \frac{\partial \varphi}{\partial y}\right)=-\rho_{v}
$$

In the two-dimensional electric field analysis, since there is no change in the physical quantity in the longitudinal direction of the horizontal conductor, the potential and the electric field can be expressed in two dimensions as follows.

$$
\begin{gathered}
\varphi=\varphi(x, y) \\
\vec{E}=E_{x}(x, y) \hat{a}_{x}+E_{y}(x, y) \hat{a}_{y}
\end{gathered}
$$

\section{ANALYSIS OF ELECTRIC FIELD FOR HORIZONTAL LIGHTNING CONDUCTOR}

For the electric field analysis, five new models are presented in comparison with the reference model, which is a circular shape. The proposed models are compared with the reference model to set three types of areas with the same, bigger, or smaller area. The cross-sectional area of the reference model was set to $8 \mathrm{~mm}$, and all models were made of copper. Fig. 2 is the proposed cross-sectional shape and horizontal conductor shape compared with the reference model. Table-II shows the materials used for horizontal conductors. Here $\mathrm{s}$ is the conductivity and $\mathrm{r}$ is the resistivity. When the horizontal conductor is installed, the modified surface is set upwards assuming that the round surface is facing the bottom.

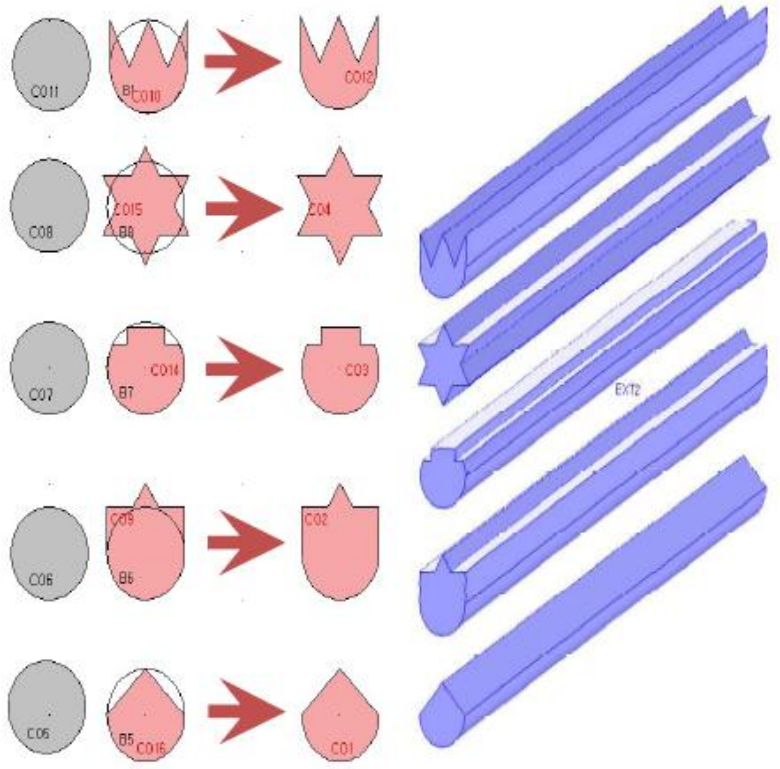

Fig. 2.The proposed cross-sectional shape and horizontal conductor shape compared with the reference model.

Table- II: Characteristics of each material for lightning conductors

\begin{tabular}{|l|l|l|l|}
\hline Material & $\mathbf{s}[\%]$ & $\mathbf{r}[\boldsymbol{\mu} \mathbf{\Omega} \cdot \mathbf{c m}]$ & Copper ratio \\
\hline silver & 106 & 1.62 & 0.94 \\
\hline annealed Cu & 100 & 1.7241 & 1.00 \\
\hline gold & 71.8 & 2.4 & 1.39 \\
\hline aluminum & 62.7 & 2.75 & 1.60 \\
\hline tungsten & 31.3 & 5.5 & 3.19 \\
\hline zinc & 29.2 & 5.9 & 3.42 \\
\hline nickel & 23.8 & 7.24 & 4.20 \\
\hline pure iron & 17.6 & 9.8 & 5.68 \\
\hline steel & $17.2 \sim 0.62$ & $10 \sim 20$ & $5.80 \sim 11.6$ \\
\hline platinum & 16.3 & 10.6 & 6.15 \\
\hline tin & 15.1 & 11.4 & 6.61 \\
\hline lead & 8.21 & 21 & 12.20 \\
\hline nichrome & 1.58 & 109 & 63.20 \\
\hline brass & $24.6 \sim 34.5$ & $5 \sim 7$ & $2.90 \sim 4.06$ \\
\hline bronze & $9.58 \sim 13.3$ & $13 \sim 18$ & $7.54 \sim 10.4$ \\
\hline
\end{tabular}

Fig. 3 shows the specific shape of the proposed 5 shapes and nomenclature in this paper. Here, Type A, Type B and Type $\mathrm{E}$ have a smaller cross-sectional area than the reference model. Type B is slightly larger than the reference model, and Type D has the same area. Each shape was artificially attempted to increase the electric field strength by adding a sharp shape to the top part. And the starting point of discharge current is fast when the electric field strength is high. 


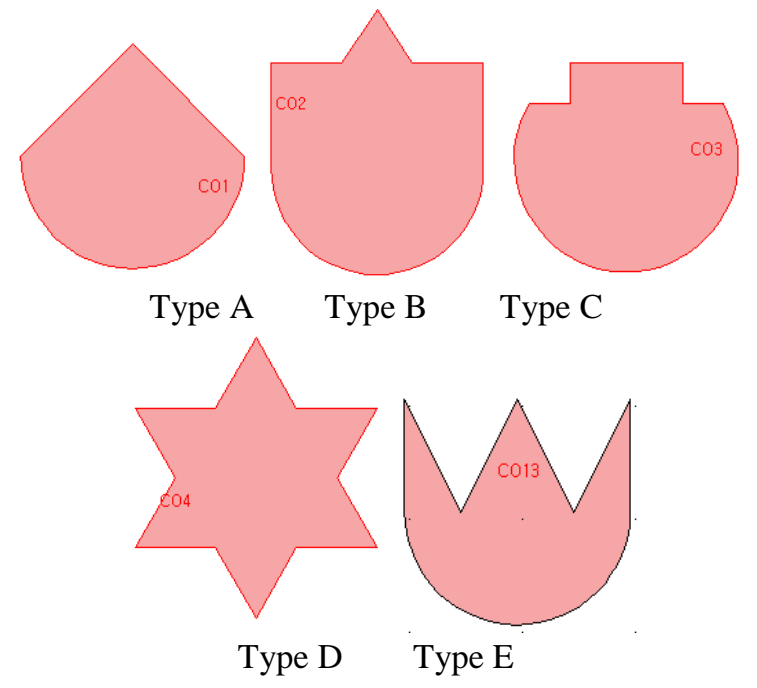

Fig. 3.The cross-sectional shape of the proposed 5 horizontal conductors.

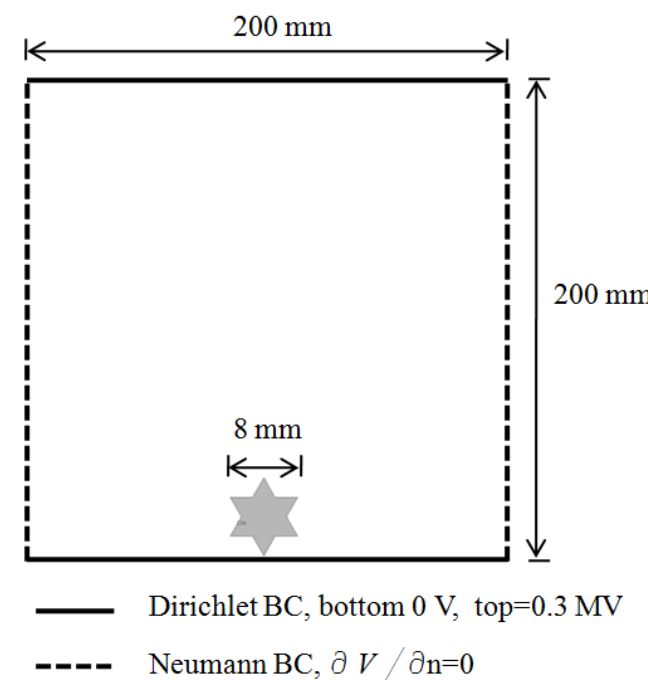

Fig. 4.Dimension and boundary condition for electrostatic field analysis.

Fig. 4 shows the dimension and boundary conditions of the analysis domain. The horizontal and vertical lengths of the space in the analysis area are $200 \mathrm{~mm}$, and the diameter of the horizontal conductor is approximately $8 \mathrm{~mm}$. The boundary condition is $0[\mathrm{~V}]$, assuming that the area below the horizontal conductor is grounded using the Dirichlet boundary condition, and the upper part of the horizontal conductor is set to 300,000 [V]. In addition, the boundary between the two sides is assumed to be the equilibrium field of the analytical domain, and the Neumann boundary condition is set so that the boundary is not changed in the normal direction of the potential.
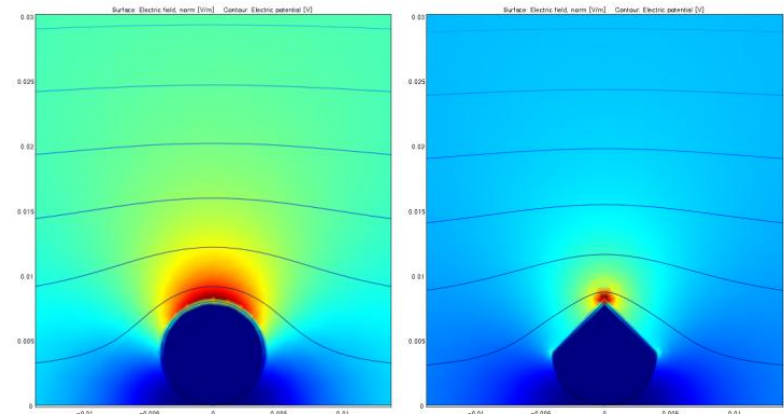

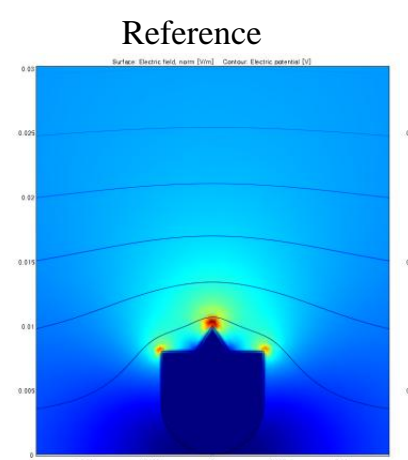

Type B

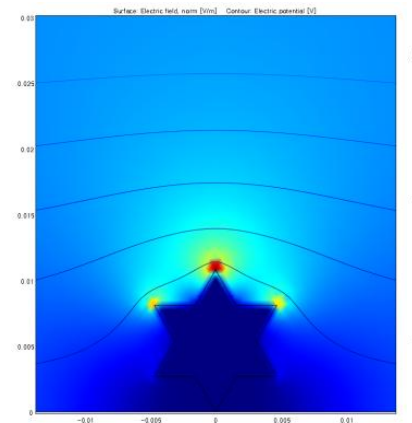

Type D
Type A

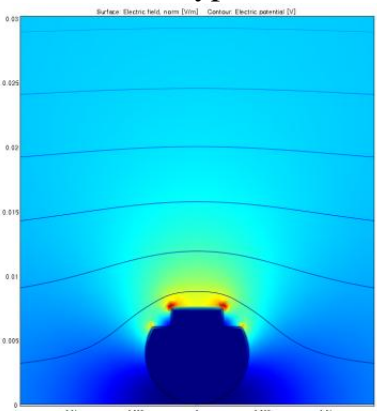

Type C

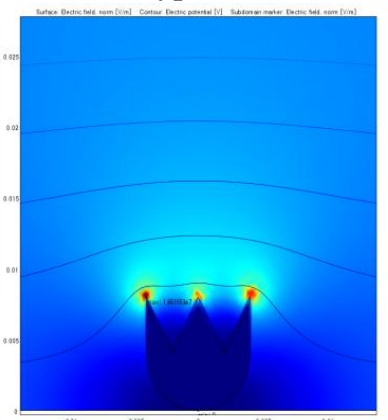

Type E
Fig. 5.Distributions of electric field intensity accord to cross-sectional shape of the horizontal lightning conductor.

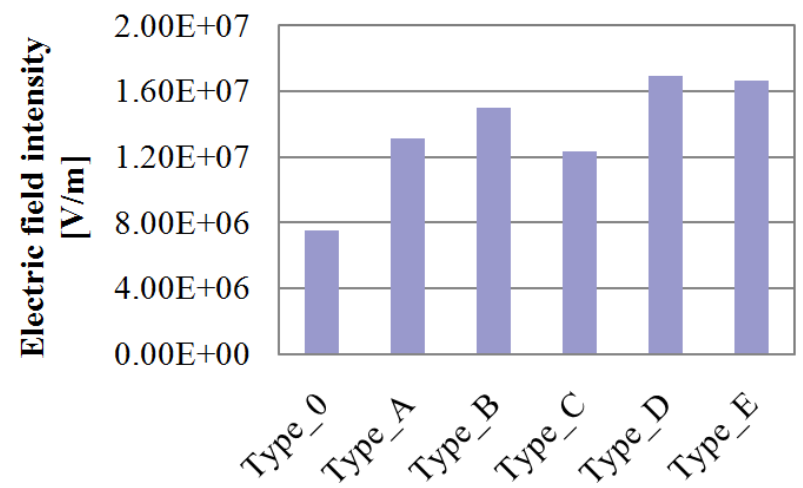

Fig. 6.Maximum values of electric field intensity accord to the proposed cross-sectional shape of the horizontal conductor.

Fig. 5 shows the distribution of the electric field intensity according to the sectional shape of the lightning horizontal conductor. In the figure, the red color is stronger in electric field strength, and the blue color is weaker. In addition, the thin solid line indicates the equi-potential line, and the smaller the interval of the equi-potential lines, the greater the intensity of the electric field can be interpreted. It was observed that the electric field was concentrated mainly in the models with the pointed shape. Fig. 6 shows the results of the electric field analysis of the proposed five cross-sectional shapes at the maximum point of the electric field.

In the reference model(circuital shape), the electric field distribution is gently distributed around the conductor and the maximum electric field value is about $4000[\mathrm{kV} / \mathrm{m}]$. In Type A, Type $\mathrm{C}$ and Type $\mathrm{E}$, the cross sectional area was smaller than the reference, 
and the maximum electric fields were increased by $75 \%$, $63 \%$ and $90 \%$, respectively. In case of Type B, the maximum value of the electric field increased by $87 \%$ when the area was slightly larger than that of the reference model. Also, in case of Type D, the cross-sectional area and the cross-sectional area of the reference model are set to the same, and the maximum electric field is increased by $92 \%$. In the case of Type E, the maximum electric field is increased by $90 \%$ under the same voltage, so that the discharge start voltage can be lowered. And this reduces the cost of material because it reduces the cross-sectional area compared with the circular shape.

\section{CONCLUSION}

Lightning horizontal conductors are one of the major lightning protection facilities that protect buildings from lightning strikes like lightning rods. The horizontal conductor is installed on the top of the building, and a conductor having a generally circular shape is used at present. In this study, five shapes were proposed to improve the cross - sectional shape of the horizontal conductor and the maximum field characteristics were analyzed through electric field analysis. Each of the proposed models was investigated by making shapes and cross-sections different from those of existing models. It is assumed that the corona discharging current is discharged early when the maximum electric field value has a high value, thereby effectively avoiding the lightning stroke. The maximum electric field value of the horizontal conductor with crown-shaped cross section was the largest as a result of electrostatic field analysis for the proposed model. This study suggests a shape that can effectively perform lightning protection by changing the shape of the horizontal conductor, which is thought to help protect the building.

\section{ACKNOWLEDGMENT}

This paper was supported by Joongbu University Research \& Development Fund, in 2019.

\section{REFERENCES}

1. Ogawa T. Lightning currents. Handbook of atmospheric electrodynamics, Volume I: CRC Press; 2017. p. 93-136.

2. International Electrotechnical C. Protection of structures against lightning-Part 1 : General principles. IEC 61024-1; 1990.

3. Lee, Ralph H., "Lightning protection of buildings," IEEE Transactions on industry applications, 3, 236-240, 1979.

4. Mackerras, D., M. Darveniza, A. C. Liew, "Review of claimed enhanced lightning protection of buildings by early streamer emission air terminals," IEE Proceedings-Science, Measurement and Technology, 144(1), 1-10, 1997.

5. Rakov, Vladimir A., "Lightning discharge and fundamentals of lightning protection," Journal of Lightning Research, 4(1), 3-11, 2012.

6. Kip AF., "Positive-point-to-plane discharge in air at atmospheric pressure," Physical Review, 54(2), 139-146, 1938.

7. Hernandez, Jesus C., Pedro G. Vidal, and Francisco Jurado, "Lightning and surge protection in photovoltaic installations," IEEE Transactions on power delivery, 23(4), 1961-1971, 2008.

8. Tausanovic M, Ignjatovic M, Cvetic J, Mijajlovic N, Pavlovic D, Heidler F., "Electric field close to lightning channel in the presence of current reflections from the ground," Mediterranean Conference on Power Generation, Transmission, Distribution and Energy Conversion 2016, 2016.

9. Petersen D, Bailey M, Hallett J, Beasley W., "Laboratory investigation of corona initiation by ice crystals and its importance to lightning,"

Quarterly Journal of the Royal Meteorological Society, 141(689), 1283-1293, 2015

10. Vogel S, Holbøll J., "Discharge characteristics in inhomogeneous fields under air flow," 25th Nordic Insulation Symposium on Materials. Components and Diagnostics, 2017.

11. Stephan KD, Krajcik R, Martin RJ., "Fluorescence caused by ionizing radiation from ball lightning: Observation and quantitative analysis," Journal of Atmospheric and Solar-Terrestrial Physics. 148, 32-38, 2016

\section{AUTHORS PROFILE}

\section{Author-1} Photo

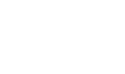

and optimal design of multi-physics system based on electromagnetic field.

Young Sun Kim He received the MS and the PhD in Electrical Engineering from the Dankook University of Seoul, Korea, in 1997 and 2006, respectively. He was a postdoctoral fellow of Research Laboratory for Electronics of MIT in 2010-2011, He is a professor of Joongbu University and his academic interests are analysis

(1)

